\title{
Article \\ Cannabidiol Application Increases Cutaneous Aquaporin-3 and Exerts a Skin Moisturizing Effect
}

\author{
Nobutomo Ikarashi ${ }^{1, *}$, Marina Shiseki ${ }^{1}$, Ryotaro Yoshida ${ }^{1}$, Keito Tabata ${ }^{1}$, Rina Kimura ${ }^{1}$, Tomofumi Watanabe ${ }^{1}$, \\ Risako Kon ${ }^{1}$, Hiroyasu Sakai ${ }^{1}$ and Junzo Kamei ${ }^{1,2, *}$ \\ 1 Department of Biomolecular Pharmacology, Hoshi University, 2-4-41 Ebara, Shinagawa-ku, \\ Tokyo 142-8501, Japan; s171108@hoshi.ac.jp (M.S.); m2119@hoshi.ac.jp (R.Y.); s171148@hoshi.ac.jp (K.T.); \\ s171077@hoshi.ac.jp (R.K.); rvimdkamagk@gmail.com (T.W.); r-kon@hoshi.ac.jp (R.K.); \\ sakai@hoshi.ac.jp (H.S.) \\ 2 Juntendo Advanced Research Institute for Health Science, Juntendo University, 2-1-1 Hongo, Bunkyo-ku, \\ Tokyo 113-8421, Japan \\ * $\quad$ Correspondence: ikarashi@hoshi.ac.jp (N.I.); j.kamei.tz@juntendo.ac.jp (J.K.); Tel.: +81-3-5498-5918 (N.I.); \\ +81-3-3815-7021 (J.K.)
}

Citation: Ikarashi, N.; Shiseki, M.; Yoshida, R.; Tabata, K.; Kimura, R.; Watanabe, T.; Kon, R.; Sakai, H.; Kamei, J. Cannabidiol Application Increases Cutaneous Aquaporin-3 and Exerts a Skin Moisturizing Effect. Pharmaceuticals 2021, 14, 879. https:// doi.org/10.3390/ph14090879

Academic Editor: Gary J. Stephens

Received: 20 July 2021

Accepted: 28 August 2021

Published: 30 August 2021

Publisher's Note: MDPI stays neutral with regard to jurisdictional claims in published maps and institutional affiliations.

Copyright: (C) 2021 by the authors Licensee MDPI, Basel, Switzerland. This article is an open access article distributed under the terms and conditions of the Creative Commons Attribution (CC BY) license (https:/ / creativecommons.org/licenses/by/ $4.0 /)$.

\begin{abstract}
Cannabidiol (CBD) is a major nonpsychotropic component of Cannabis sativa with various pharmacological activities. In this study, we investigated the skin moisturizing effect of CBD and its mechanism. A 1\% CBD solution was applied daily to skin of HR-1 hairless (Seven-week-old, male) for 14 days. The dermal water content in CBD-treated mice was significantly increased compared to that in the control group. Furthermore, no inflammatory reaction in the skin and no obvious skin disorders were observed. The mRNA expression levels of loricrin, filaggrin, collagen, hyaluronic acid degrading enzyme, hyaluronic acid synthase, ceramide degrading enzyme, and ceramide synthase in the skin were not affected by the application of CBD. However, only aquaporin-3 (AQP3), a member of the aquaporin family, showed significantly higher levels in the CBD-treated group than in the control group at both the mRNA and protein levels. It was revealed that CBD has a moisturizing effect on the skin. In addition, it is possible that increased expression of AQP3, which plays an important role in skin water retention, is a contributor to the mechanism. CBD is expected to be developed in the future as a cosmetic material with a unique mechanism.
\end{abstract}

Keywords: cannabidiol; aquaporin-3; skin; Cannabis sativa; cosmetics; moisturizing effect

\section{Introduction}

The skin is an organ that exists at the boundary between the external environment and the internal environment of a living body. Dermal water content is related to the elasticity of the skin and the formation of wrinkles. In fact, in elderly individuals, dermal water content is reduced, elasticity is reduced, and wrinkles form [1]. Dermal water content is controlled by various moisturizing factors, such as collagen [2], ceramide [3,4], and hyaluronic acid [5,6]. Moreover, loricrin [7] and filaggrin [8] are involved in the barrier function of the skin and are also important for skin moisturization. In addition to these factors, it has become clear that the water channels known as aquaporins (AQPs) play important roles in skin water retention. In particular, AQP3 is predominantly expressed in the cell membrane of skin keratinocytes, and it has been reported that AQP3-knockout mice have dry skin and reduced skin elasticity compared to wild-type mice $[9,10]$. Moreover, cutaneous AQP3 are implicated in the development of several skin diseases, such as eczema, diabetic xeroderma, psoriasis, hyperproliferative skin disorders, or melanoma, among others, and are very important molecule that controls skin function [11]. Currently, various substances and natural products that increase these moisturizing factors and AQPs have been found and are expected to be used as cosmetic materials.

Cannabidiol (CBD) is a major nonpsychotropic component of Cannabis sativa. CBD is known to exert various pharmacological actions, such as anxiolytic [12], antipsychotic [13], 
anti-inflammatory [14], antiemetic [15], and antidiabetic actions [16], and active research is being conducted. CBD has also been found to have effects on atopic dermatitis, pruritus, and acne $[17,18]$, and research on the effects of CBD on the skin is being conducted. Moreover, it has been reported that when CBD is applied to skin, dermal water content and the elasticity of the skin are increased [19], and there is a protective effect against ultraviolet rays [20]. As mentioned previously, $\mathrm{CBD}$ is attracting attention as a cosmetic material. However, scientific evidence is still scarce, and it remains unclear how CBD affects the genes that regulate skin function.

Therefore, in this study, we aimed to generate scientific evidence on the usefulness of CBD by investigating the skin moisturizing effect of CBD. Specifically, CBD was applied to the skin of hairless mice, and dermal water content was measured. We also investigated the effect of $\mathrm{CBD}$ on the expression of genes (loricrin, filaggrin, collagen, hyaluronic acid degrading enzyme, hyaluronic acid synthase, ceramide degrading enzyme, ceramide synthase, and AQPs) involved in the maintenance of dermal water content.

\section{Results}

\subsection{Skin Tissue Findings and Inflammatory Reactions}

Skin tissue was analyzed after the application of CBD for 14 days by hematoxylin and eosin (HE) staining. The results showed that, even when CBD was applied, the skin tissue was similar to that in the control group, and no obvious skin tissue disorders were observed (Figure 1A). In addition, the mRNA expression levels of Tnfa and Cox2, which are increased during inflammation, were not altered by the application of CBD (Figure 1B,C).

Based on the above results, no significant skin toxicity was observed at the CBD treatment concentration in this experiment.

(A)

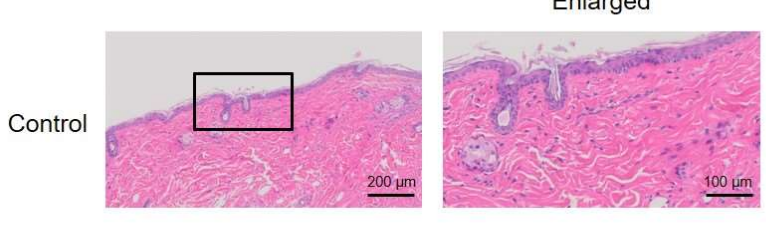

Enlarged

CBD

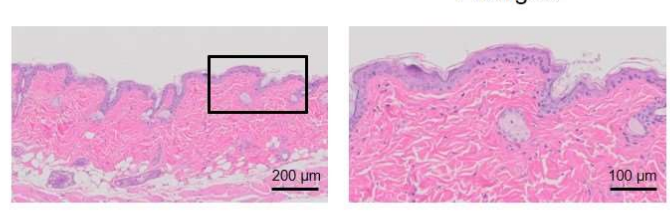

(B)

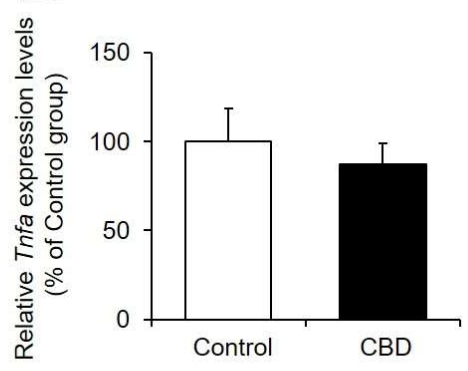

(C)

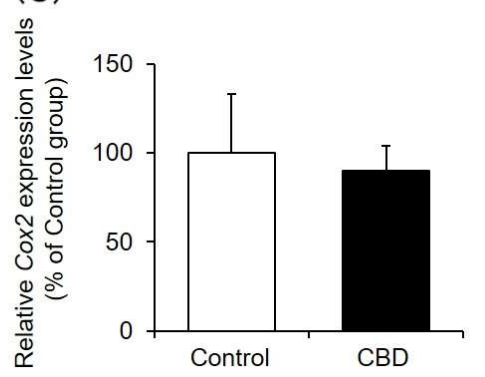

Figure 1. Skin tissue findings and inflammatory reactions. A $1 \%$ CBD solution was applied to the back skin of mice for 14 days. After the treatment, the skin was removed, and the tissue was assessed by HE staining (A). The mRNA expression levels of Tnfa (B) and Cox2 (C) in the skin were analyzed by real-time RT-PCR $(n=6$, means $\pm \mathrm{SD})$.

\subsection{Dermal Water Content and Transepidermal Water Loss (TEWL)}

Dermal water content and TEWL after CBD was applied for 14 days were measured. The dermal water content in the CBD-treated group was significantly increased compared to that in the control group (Figure 2A). In contrast, TEWL in the CBD-treated group was similar to that in the control group (Figure 2B). 
In general, when the barrier function of the skin is decreased, TEWL increases. Therefore, these results showed that when CBD was applied to mouse skin for 14 days, dermal water content increased while normal barrier function was maintained.

(A)

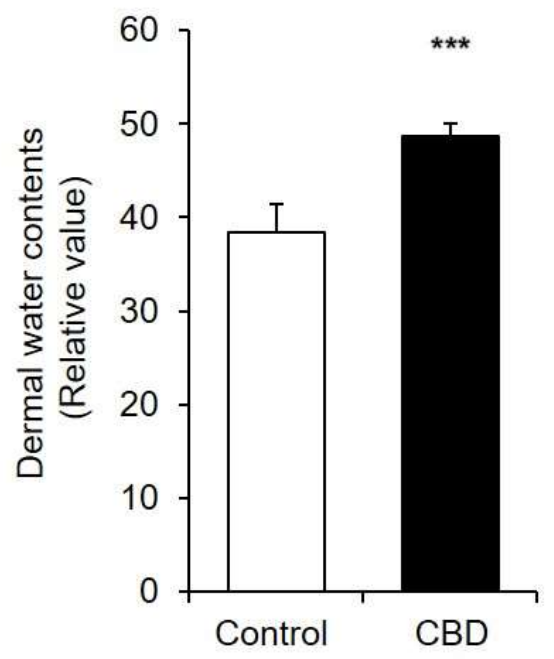

(B)

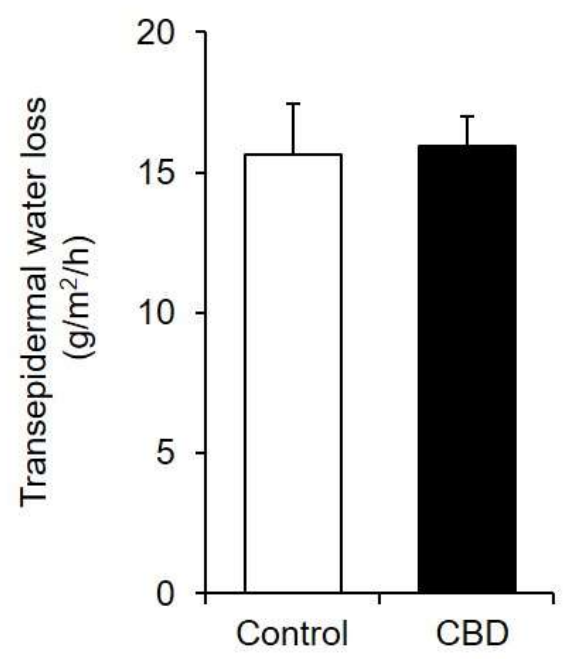

Figure 2. Dermal water content and TEWL. A $1 \%$ CBD solution was applied to the back skin of mice for 14 days. After the treatment, dermal water content (A) and TEWL (B) were measured $(n=6$, means $\pm \mathrm{SD},{ }^{* * *} p<0.001$ vs. the control group).

\subsection{Expression Levels of Skin Moisturizing Factor-Related Genes}

Dermal water content is regulated by loricrin, filaggrin, collagen, hyaluronic acid, ceramide and other factors. Therefore, whether the expression levels of genes involved in this process were changed by CBD application was investigated.

The mRNA expression levels of Lor and Flg in the skin after the application of a $1 \%$ CBD solution for 14 days were almost the same as those in the control group. The expression level of collagen (Col1a1 and Col1a2) was not different between the CBD-treated group and the control group. Furthermore, hyaluronan degrading enzyme (Hyal1), hyaluronan synthase (Has2), ceramide degrading enzymes (Acer1 and Asah1), and ceramide synthases (Sptlc1 and Sptlc2) were not affected by the application of CBD (Figure 3).

\subsection{AQP $m R N A$ and Protein Expression Levels in the Skin}

In mammals, 15 isoforms of AQPs are expressed [21] and involved in intracellular and extracellular water transport (in mice, AQP10 is a pseudogene [22]). Therefore, whether the expression level of AQP was altered in the skin after the application of a 1\% CBD solution for 14 days was investigated.

Comprehensive analysis of Aqp mRNA expression levels by real-time RT-PCR showed that Aqp1, Aqp2, Aqp3, Aqp4, Aqp7, Aqp9, and Aqp11 were present in mouse skin. Of these, only the mRNA expression level of Aqp3 was confirmed to be significantly increased in the CBD-treated group compared with the control group (Figure 4).

When the protein expression level of AQP3 was analyzed by Western blotting, two bands were detected. The band at approximately $27 \mathrm{kDa}$ was nonglycosylated, and the band at approximately $30-40 \mathrm{kDa}$ was glycosylated. Since there was no difference in water permeability between nonglycosylated AQP and glycosylated AQP [23-25], the total of these band densities was used for analysis in this study. The protein expression level of $\mathrm{AQP3}$ after $\mathrm{CBD}$ treatment was significantly higher than that in the control group (Figure 5).

These results showed that CBD enhanced the transcription of Aqp3 in the skin and increased the protein expression level of AQP3. 
《Lor》
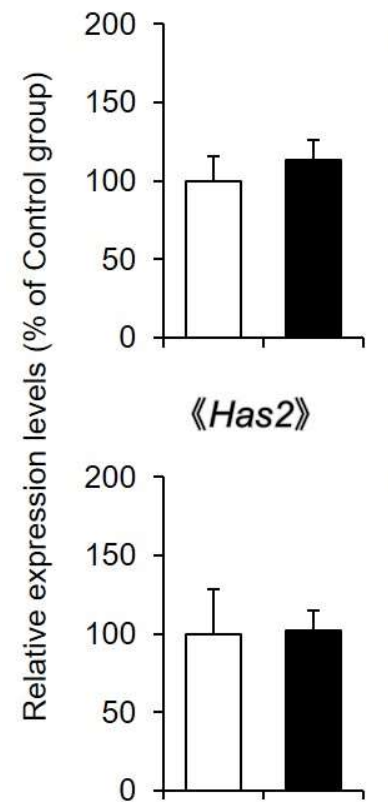

《Flg》
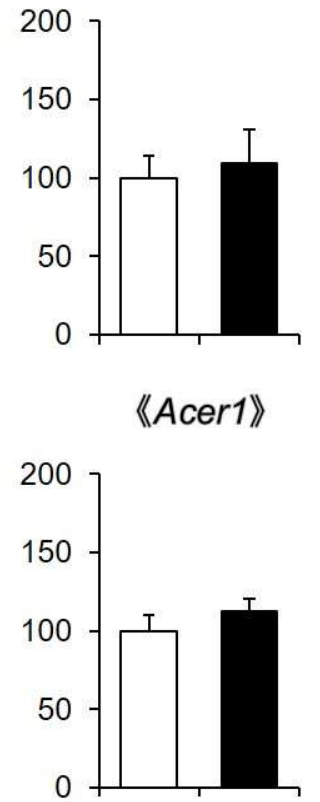

《Col1a1》
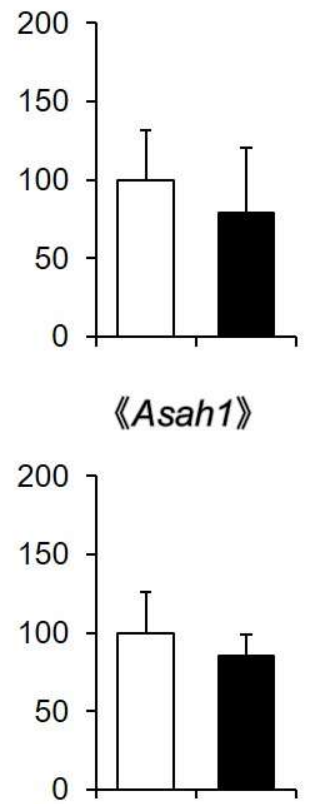

《Col1a2》

《Hyal1》
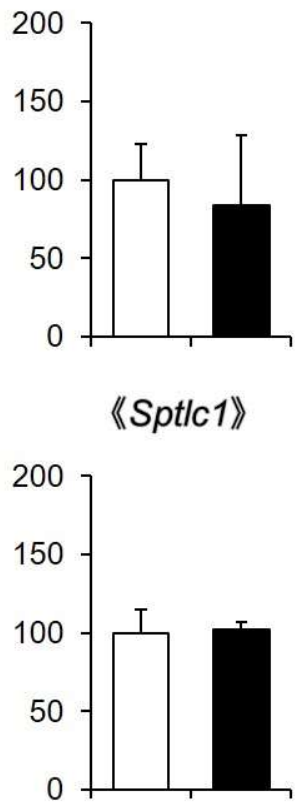
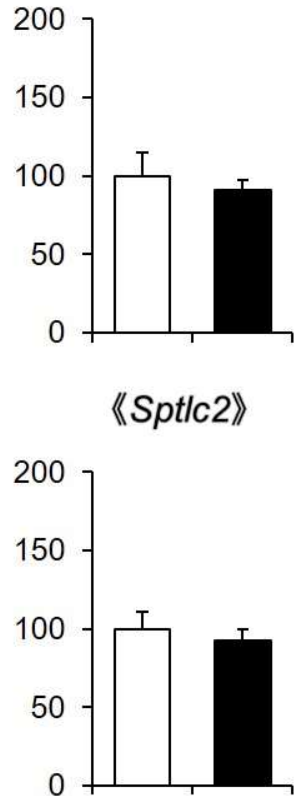

Figure 3. Expression levels of skin moisturizing factor-related genes. A 1\% CBD solution was applied to the back skin of mice for 14 days (black). A solvent was applied to the control group (white). After the treatment, the mRNA expression levels of Lor, Flg, Col1a1, Col1a2, Hyal1, Has2, Acer1, Asah1, Sptlc1, and Sptlc2 in the skin were analyzed by real-time RT-PCR $(n=6$, means $\pm \mathrm{SD})$.

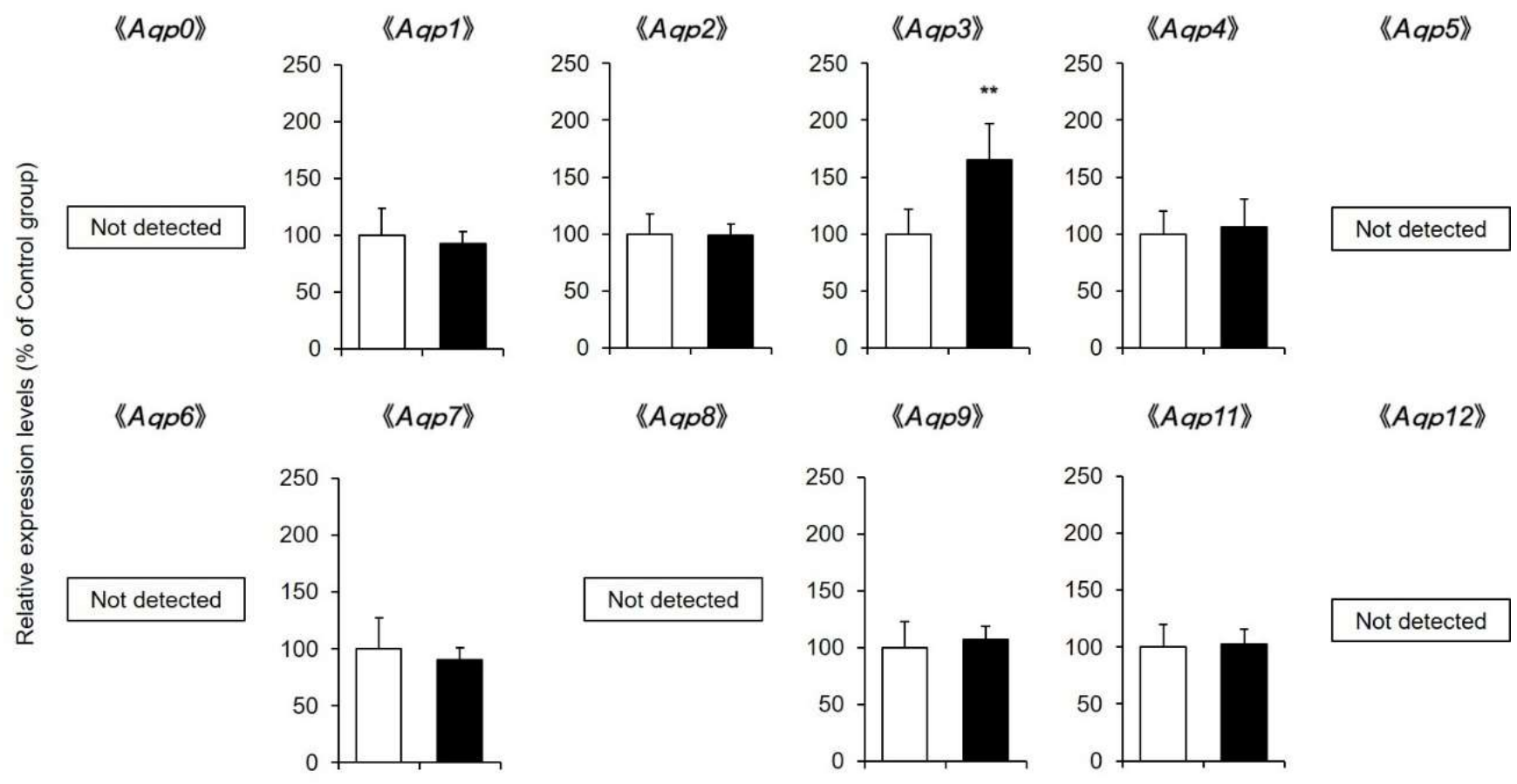

Figure 4. Aqp mRNA expression levels in the skin. A 1\% CBD solution was applied to the back skin of mice for 14 days (black). A solvent was applied to the control group (white). After the treatment, the mRNA expression levels of Aqp in the skin were analyzed by real-time RT-PCR $\left(n=6\right.$, means $\pm \mathrm{SD},{ }^{* *} p<0.01$ vs. the control group). 

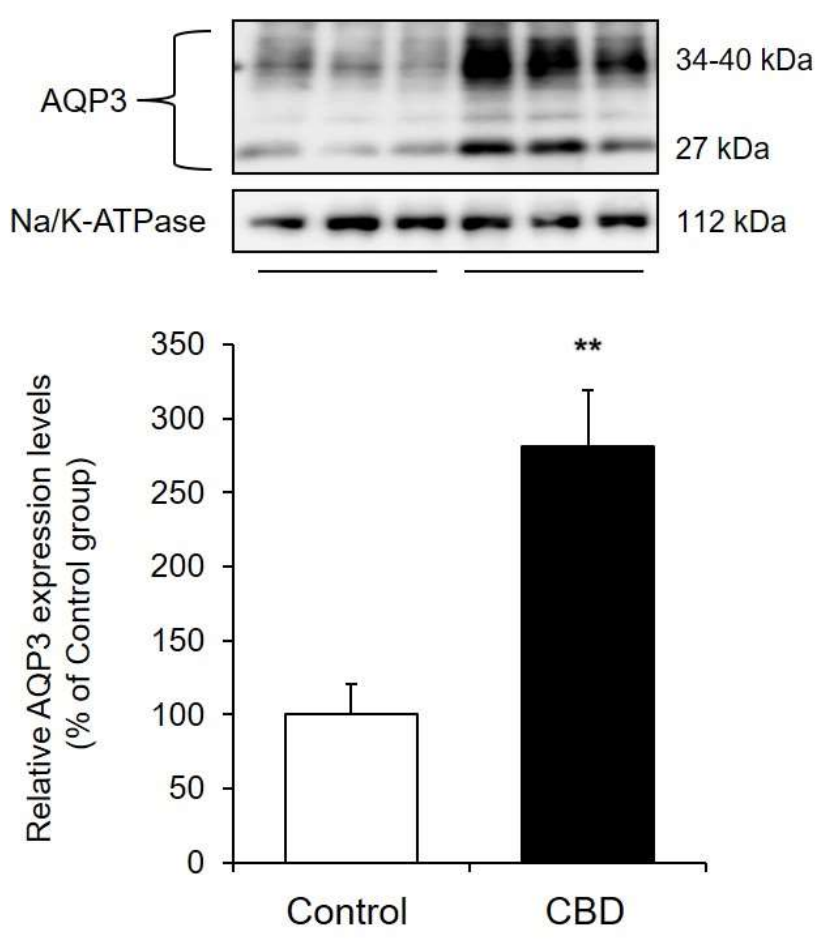

Figure 5. AQP3 protein expression levels in the skin. A 1\% CBD solution was applied to the back skin of mice for 14 days. After the treatment, the protein expression level of AQP3 in the skin was analyzed by Western blotting ( $n=6$, means $\pm \mathrm{SD}$, ${ }^{* *} p<0.01$ vs. the control group).

\section{Discussion}

CBD has been reported to have improving effects on various skin diseases [17-20]. In this study, we verified the skin moisturizing effect of CBD and analyzed its mechanism.

Laura Casares et al. have shown that the application of a 1\% CBD solution to the skin of 6-month-old mice induces keratinocyte proliferation, which may be involved in wound healing [26]. Therefore, as in a previous report, a 1\% CBD solution was applied to mouse skin every day, and various examinations were conducted. The results showed that dermal water content in the CBD-treated group increased approximately 1.3 times compared with that in the control group, and a significant difference was observed (Figure 2A). Moreover, no skin inflammation was observed (Figure 1), and the skin barrier function was normal (Figure 2B). These findings show that CBD exhibits a skin moisturizing effect and may be considered useful as a cosmetic material. When a 3\% CBD solution was applied to mouse skin, no inflammatory reaction was observed, but TEWL increased and dermal water content decreased to the same level as in the control group (data not shown). Therefore, an optimal concentration was considered when applying CBD to the skin.

Dermal water content is regulated by moisturizing factors such as loricrin, filaggrin, collagen, hyaluronic acid, and ceramide. Therefore, we investigated the effect of CBD on the expression of genes involved in these processes. CBD did not affect the mRNA expression levels of loricrin, filaggrin, collagen, hyaluronan degrading enzyme, hyaluronan synthase, ceramide degrading enzyme, or ceramide synthase in the skin (Figure 3). Therefore, it is unlikely that $\mathrm{CBD}$ exerted a skin moisturizing effect by changing the amount of these moisturizing factors.

In recent years, it has been reported that the water channel known as AQP plays an important role in skin water retention $[9,10]$, and active research is being conducted. AQP is a water-permeable protein expressed on the cell membrane, and 15 isoforms of AQPs are known to exist in mammals. Aqp1, Aqp2, Aqp3, Aqp4, Aqp7, Aqp9, and Aqp11 mRNA were detected in the skin of the mice in this study (Figure 4). Of these, it was revealed that only the mRNA expression level of Aqp3 was significantly increased by the application of CBD compared with that in the control group (Figure 4). The protein expression level of 
AQP3 was also significantly higher in the CBD-treated group than in the control group (Figure 5). AQP3 is predominantly expressed in the cell membrane of skin keratinocytes and is classified as an aquaglyceroporin, which is responsible for transporting glycerol as well as water [27]. It has been reported that AQP3-knockout mice have dry skin and reduced skin elasticity compared to wild-type mice [10]. In addition, the expression level of AQP3 in the skin of aged mice was lower than that in young mice, suggesting that AQP3 may be involved in the decrease in dermal water content in old age [28]. Furthermore, AQP3 is decreased at the onset of various pathological conditions (diabetes mellitus [29,30], vitiligo [31,32], and psoriasis [33]) in which dry skin is observed. In addition, when mice are treated with the anticancer drug, which causes marked dry skin as a side effect, dry skin and a decrease in AQP3 were also observed [34]. Thus, it can be hypothesized that AQP3 is a key molecule that plays an important role in skin water retention. Since CBD increased the expression of AQP3 in the skin, it was thought that this effect may be involved in the skin moisturizing effect of CBD.

AQP3-induced glycerol transport contributes not only skin water retention but also to skin protection. AQP3 facilitates glycerol movement in several cells of skin layers, including the epidermal keratinocytes [10,35] or hypodermal adipocytes [36]. It was reported that topic or systemic glycerol administration or AQP3 re-expression in keratinocytes reverse the phenotype of skin abnormalities in Aqp3-deficient mice [35,37]. In this study, although the skin glycerol concentration in CBD-treated mice was not measured, it is possible that the increase in glycerol associated with the increase in AQP3 is also involved in the increase in dermal water content.

AQP3 is known to be present not only in keratinocytes but also in hypodermal adipocytes. However, its expression level is very low, and it is a fact that the epidermal layer is strongly stained when the skin is performed immunohistochemistry of AQP3 [11,28]. As AQP3 in the epidermal layer is mainly involved in the increase in dermal water content, we believe that the increase in dermal water content due to CBD treatment is mainly due to the increase in AQP3 in the epidermal layer.

Why did the application of CBD increase AQP3 in the skin? So far, various cytokines, such as tumor necrosis factor- $\alpha$ (TNF- $\alpha$ ) or transforming growth factor- $\beta$ (TGF- $\beta$ ), can change the expression levels of aquaglyceroporins AQP3, AQP7, and AQP11 in subcutaneous adipocytes [38,39]. In this study, it was clarified that the application of CBD to mouse skin did not change the cutaneous Tnfa mRNA expression level, and at this time, only Aqp 3 increased; no correlation was found between Tnfa and Aqps transcript levels. Therefore, it is unlikely that these cytokines are involved in the increased Aqp3 expression.

In general, $\mathrm{CBD}$ acts on cannabinoid receptors to exert various pharmacological actions [40]. On the other hand, it has also been reported that CBD increases the activity of peroxisome proliferator-activated receptor- $\gamma(\operatorname{PPAR} \gamma)$ and exerts a pharmacological effect on various cells [41,42]. PPAR $\gamma$ is expressed in skin keratinocytes, and it has been revealed that PPAR $\gamma$ agonists increase the expression level of AQP3 in keratinocytes [43]. In this study, there was no change in the mRNA expression level of Pparg in mouse skin treated with CBD (data not shown). Although the mechanism by which CBD increases AQP3 in mouse skin is unclear, it is possible that CBD activates PPAR $\gamma$ in keratinocytes and increases AQP3, which requires further study.

The results of this study show that CBD has a skin moisturizing effect. In addition, it is possible that the increased expression of AQP3, which plays an important role in skin water retention, is involved as one of the mechanisms of action. Currently, there is an active search for substances and natural products that increase cutaneous AQP3 expression. CBD is expected to be applied in the future as a cosmetic material that has the unique effect of increasing AQP3. 


\section{Materials and Methods}

\subsection{Materials}

CBD crystalline powder (Batch No. CB99020171A) was provided by PharmaHemp Laboratories (Ljubljana, Slovenia) and used in this study. This powder contained $99.34 \%$ CBD.

\subsection{Animals and Treatment}

Seven-week-old male HR-1 hairless mice were purchased from Hoshino Laboratory Animals, Corp. (Ibaraki, Japan). The mice were divided into two groups $(n=6)$ : a control group and a CBD-treated group. In the control group, an aqueous solution containing $10 \%$ propylene glycol and dimethyl sulfoxide was applied to the skin on the backs of the mice for 14 days. In the CBD-treated group, an aqueous solution containing 1\% CBD was applied to the skin of the mice for 14 days. After the application was completed, dermal water content (Corneometer CM825; Courage \& Khazaka, Cologne, Germany) and TEWL (Tewameter TM300; Courage \& Khazaka, Cologne, Germany) were measured. The back skin was removed under isoflurane anesthesia, and skin tissue damage was observed by HE staining. To analyze mRNA and protein expression, the back skin was instantly frozen in liquid nitrogen and stored at $-80^{\circ} \mathrm{C}$.

\subsection{HE Staining}

The skin was soaked in $4 \%$ formaldehyde solution to fix the tissue. Tissue samples were embedded in paraffin and mounted on glass slides. The slides were deparaffinized, stained with HE, and observed under a microscope. The slides were blindly evaluated by a pathologist and evaluated for skin damage.

\subsection{Real-Time RT-PCR}

Total RNA was extracted by homogenizing approximately $20 \mathrm{mg}$ of skin with Tri reagent (Sigma-Aldrich Corp., St. Louis, MO, USA). cDNA was synthesized from total RNA using a high-capacity cDNA synthesis kit (Applied Biosystems, Foster City, CA, USA). The cDNA solution, primers (Table 1), and Sso advanced universal SYBR Green SuperMix (Bio-Rad Laboratories, Hercules, CA, USA) were combined, and the mRNA expression level was analyzed using a real-time PCR system. The mRNA expression level was normalized using 18S rRNA. Genes with more than 35 cycles were not detected.

\subsection{Western Blotting}

Approximately $150 \mathrm{mg}$ of skin was homogenized in dissecting buffer. According to past reports [44], centrifugation was performed to prepare a sample solution that was used for Western blotting. The sample solution was diluted with loading buffer after the protein concentration was measured by the BCA method. The proteins were separated by electrophoresis and then transferred to a polyvinylidene difluoride membrane. The membrane was blocked with blocking buffer and then incubated with primary antibodies [rabbit anti-rat AQP3 (Alomone Labs, Jerusalem, Israel), mouse anti-rabbit Na/K-ATPase (Merck Millipore, Darmstadt, Germany)] and secondary antibodies [donkey anti-rabbit IgG-HRP (Santa Cruz Biotechnology Inc., Santa Cruz, CA, USA) and goat anti-mouse IgGHRP antibody (Merck Millipore, Darmstadt, Germany). The membrane was reacted with enhanced chemiluminescent prime Western blotting detection reagents (GE Healthcare, Fairfield, CT, USA), and bands were detected by an immunoimage analyzer (ImageQuant LAS500, GE Healthcare). The protein expression level was normalized using Na/K-ATPase.

\subsection{Statistical Analysis}

The values are shown as the mean \pm standard deviation (SD). Normality was tested through Shapiro-Wilk test, and homogeneity of variances tested through F test. Based on the normality of distribution and variance homogeneity, Student's $t$-test was used for analysis, and $p<0.05$ was considered significant. 
Table 1. Primer sequences.

\begin{tabular}{|c|c|c|c|}
\hline Gene & Accession Number & Forward $\left(5^{\prime}\right.$ to $\left.3^{\prime}\right)$ & Reverse $\left(5^{\prime}\right.$ to $\left.3^{\prime}\right)$ \\
\hline Tnfa & NM_013693 & AAGCCTGTAGCCCACGTCGTA & GGCACCACTAGTTGGTTGTCTTTG \\
\hline $\operatorname{Cox} 2$ & NM_011198 & CAGGGCCCTTCCTCCCGTAG & GCCTTGGGGGTCAGGGATGA \\
\hline Lor & NM_008508 & GCCGATGGGCTTAACTTTCT & CAGGATACACCTTGAGCGAC \\
\hline $\mathrm{Flg}$ & NM_001013804 & AAGGAAATCAGTCTTGCCGT & CTGACCTTCTGAGACACACC \\
\hline Col1a1 & NM_007742 & CCCGAGGTATGCTTGATCTG & GGTGATACGTATTCTTCCGGG \\
\hline Col1a2 & NM_007743 & TCTCACTCCTGAAGGCTCTA & GTAGTAATCGCTGTTCCACTC \\
\hline Hyal1 & NM_008317 & TTTCTTTGAGCCTGGAGCTA & GTAGTTTCCTTTCGTTGGCT \\
\hline Has2 & NM_008216 & CGTGGATTATGTACAGGTGTGT & CCAACACCTCCAACCATAGG \\
\hline Acer1 & NM_175731 & CCGAGTTCTACAATACGTTCA & CATACGGATGCATGAGGAAC \\
\hline Asah1 & NM_019734 & CTGTCCTCAACAAGCTGACTG & TCTCAGTACGTCCTCAAGGC \\
\hline Sptlc1 & NM_009269 & TCСССТTCCAGAACTGGTTAAA & CCATAGTGCTCGGTGACT \\
\hline Sptlc2 & NM_011479 & GTCAGGAAATTGGAAACCTGG & AGCTTCCACACCTAAGAACC \\
\hline Aqp0 & NM_008600 & TGCTCTGCATCTTTGCTACA & GCACCAGTGTAATACATCCCA \\
\hline Aqp1 & NM_007472 & CTGCTGGCGATTGACTACACT & TCATAGATGAGCACTGCCAGG \\
\hline Aqp2 & NM_009699 & CTGGCTGTCAATGCTCTCCAC & TTGTCACTGCGGCGCTCATC \\
\hline Aqp3 & NM_016689 & CCTTGTGATGTTTGGCTGTGG & GGAAGCACATTGCGAAGGTC \\
\hline Aqp 4 & NM_009700 & GAGTCACCACGGTTCATGGA & CGTTTGGAATCACAGCTGGC \\
\hline Aqp5 & NM_009701 & GCTGGAGAGGCAGCATTG & CACCCAAGTGTCCCATCATG \\
\hline Aqp6 & NM_175087 & AGTCCATTGGATCTTCTGGGT & GTCTTGGTGTCAGGGAACAA \\
\hline Aqp7 & NM_007473 & GCTTGGTCTGCTGCTTCAG & GGAACTCTGCCAGAAACTCTC \\
\hline Aqp8 & NM_007474 & GGCTTCTCTGTCATTGTGGA & TCCGATGAGGAGCCTAATGA \\
\hline Aqp9 & NM_022026 & TGAGCCATTAGGAGAGACCTT & ACСTCCAACTTTAGTCCACCA \\
\hline Aqp11 & NM_175105 & AGTCTGACCAAGTACCATTACGA & TGCATAGGCCAAAAAGGTGAT \\
\hline Aqp12 & NM_177587 & GCCTGGAGATGCGAGTGTT & GCCGACAGTTTCAGCAGAG \\
\hline $18 \mathrm{~s} r \mathrm{RNA}$ & NR_003278 & GTCTGTGATGCCCTTAGATG & AGCTTATGACCCGCACTTAC \\
\hline
\end{tabular}

Tnfa: tumor necrosis factor- $\alpha$, Cox2: cyclooxygenase-2, Lor: loricrin, Flg: filaggrin, Col1a1: collagen type I alpha 1 chain, Col1a2: collagen type I alpha 2 chain, Hyal1: hyaluronidase 1, Has2: hyaluronic acid synthase 2, Acer1: alkaline ceramidase 1, Asah1: N-acylsphingosine amidohydrolase 1, Sptlc1: serine palmitoyltransferase 1, Sptlc2: serine palmitoyltransferase 2.

\section{Conclusions}

It was revealed that $\mathrm{CBD}$ has a moisturizing effect on the skin. In addition, it is possible that increased expression of AQP3, which plays an important role in skin water retention, is a contributor to the mechanism. CBD is expected to be developed in the future as a cosmetic material with a unique mechanism.

Author Contributions: Conceptualization, N.I. and J.K.; methodology, N.I., M.S., R.Y. and J.K.; formal analysis, N.I., M.S., R.Y., K.T., R.K. (Rina Kimura) and T.W.; writing-original draft preparation, N.I., M.S., R.K. (Risako Kon) and H.S.; writing—review and editing, supervision, project administration, and funding acquisition, J.K. All authors have read and agreed to the published version of the manuscript.

Funding: This research was funded by the following grants; Grant-in Aid for Scientific Research (C) from the Japan Society for the Promotion of Science, grant number 19K08783. This research was supported by the PIA Co., Ltd. and Elixinol Co., Ltd.

Institutional Review Board Statement: The study was conducted according to the guidelines of the Declaration of Helsinki, and approved by the Institutional Review Board of Hoshi University (approval number: 19-137, 12 November 2019).

Informed Consent Statement: Not applicable.

Data Availability Statement: Data is contained within the article.

Acknowledgments: We thank Yui Shinozaki, Ayuka Miyazawa, Yui Nishinaka, and Haruka Kawai (Department of Biomolecular Pharmacology, Hoshi University) for their technical assistance.

Conflicts of Interest: The authors declare no conflict of interest. The funders had no role in the design of the study; in the collection, analyses, or interpretation of data; in the writing of the manuscript, or in the decision to publish the results. 


\section{References}

1. Ghadially, R.; Brown, B.E.; Sequeira-Martin, S.M.; Feingold, K.R.; Elias, P.M. The aged epidermal permeability barrier. Structural, functional, and lipid biochemical abnormalities in humans and a senescent murine model. J. Clin. Investig. 1995, 95, 2281-2290. [CrossRef] [PubMed]

2. Liu, T.; Li, N.; Yan, Y.Q.; Liu, Y.; Xiong, K.; Liu, Y.; Xia, Q.M.; Zhang, H.; Liu, Z.D. Recent advances in the anti-aging effects of phytoestrogens on collagen, water content, and oxidative stress. Phytother. Res. 2020, 34, 435-447. [CrossRef] [PubMed]

3. Jensen, J.M.; Forl, M.; Winoto-Morbach, S.; Seite, S.; Schunck, M.; Proksch, E.; Schutze, S. Acid and neutral sphingomyelinase, ceramide synthase, and acid ceramidase activities in cutaneous aging. Exp. Dermatol. 2005, 14, 609-618. [CrossRef]

4. Li, Q.; Fang, H.; Dang, E.; Wang, G. The role of ceramides in skin homeostasis and inflammatory skin diseases. J. Dermatol. Sci. 2020, 97, 2-8. [CrossRef] [PubMed]

5. Ghersetich, I.; Lotti, T.; Campanile, G.; Grappone, C.; Dini, G. Hyaluronic acid in cutaneous intrinsic aging. Int. J. Dermatol. 1994, 33, 119-122. [CrossRef]

6. Papakonstantinou, E.; Roth, M.; Karakiulakis, G. Hyaluronic acid: A key molecule in skin aging. Dermatoendocrinology 2012, 4, 253-258. [CrossRef]

7. Nithya, S.; Radhika, T.; Jeddy, N. Loricrin-an overview. J. Oral Maxillofac. Pathol. 2015, 19, 64-68. [CrossRef]

8. Sandilands, A.; Sutherland, C.; Irvine, A.D.; McLean, W.H. Filaggrin in the frontline: Role in skin barrier function and disease. J. Cell Sci. 2009, 122, 1285-1294. [CrossRef]

9. Bollag, W.B.; Aitkens, L.; White, J.; Hyndman, K.A. Aquaporin-3 in the epidermis: More than skin deep. Am. J. Physiol. Cell Physiol. 2020, 318, C1144-C1153. [CrossRef]

10. Hara, M.; Ma, T.; Verkman, A.S. Selectively reduced glycerol in skin of aquaporin-3-deficient mice may account for impaired skin hydration, elasticity, and barrier recovery. J. Biol. Chem. 2002, 277, 46616-46621. [CrossRef] [PubMed]

11. da Silva, I.V.; Silva, A.G.; Pimpao, C.; Soveral, G. Skin aquaporins as druggable targets: Promoting health by addressing the disease. Biochimie 2021, 188, 35-44. [CrossRef] [PubMed]

12. Blessing, E.M.; Steenkamp, M.M.; Manzanares, J.; Marmar, C.R. Cannabidiol as a Potential Treatment for Anxiety Disorders. Neurotherapeutics 2015, 12, 825-836. [CrossRef]

13. Zanelati, T.V.; Biojone, C.; Moreira, F.A.; Guimaraes, F.S.; Joca, S.R. Antidepressant-like effects of cannabidiol in mice: Possible involvement of 5-HT1A receptors. Br. J. Pharmacol. 2010, 159, 122-128. [CrossRef] [PubMed]

14. Kaplan, B.L.; Springs, A.E.; Kaminski, N.E. The profile of immune modulation by cannabidiol (CBD) involves deregulation of nuclear factor of activated T cells (NFAT). Biochem. Pharmacol. 2008, 76, 726-737. [CrossRef]

15. Rock, E.M.; Sullivan, M.T.; Collins, S.A.; Goodman, H.; Limebeer, C.L.; Mechoulam, R.; Parker, L.A. Evaluation of repeated or acute treatment with cannabidiol (CBD), cannabidiolic acid (CBDA) or CBDA methyl ester (HU-580) on nausea and/or vomiting in rats and shrews. Psychopharmacology 2020, 237, 2621-2631. [CrossRef] [PubMed]

16. Weiss, L.; Zeira, M.; Reich, S.; Har-Noy, M.; Mechoulam, R.; Slavin, S.; Gallily, R. Cannabidiol lowers incidence of diabetes in non-obese diabetic mice. Autoimmunity 2006, 39, 143-151. [CrossRef] [PubMed]

17. Baswan, S.M.; Klosner, A.E.; Glynn, K.; Rajgopal, A.; Malik, K.; Yim, S.; Stern, N. Therapeutic Potential of Cannabidiol (CBD) for Skin Health and Disorders. Clin. Cosmet. Investig. Dermatol. 2020, 13, 927-942. [CrossRef]

18. Sheriff, T.; Lin, M.J.; Dubin, D.; Khorasani, H. The potential role of cannabinoids in dermatology. J. Dermatol. Treat 2020, 31, 839-845. [CrossRef]

19. Palmieri, B.; Laurino, C.; Vadala, M. A therapeutic effect of cbd-enriched ointment in inflammatory skin diseases and cutaneous scars. Clin. Ter. 2019, 170, e93-e99. [CrossRef]

20. Atalay, S.; Gegotek, A.; Wronski, A.; Domigues, P.; Skrzydlewska, E. Therapeutic application of cannabidiol on UVA and UVB irradiated rat skin. A proteomic study. J. Pharm. Biomed. Anal. 2021, 192, 113656. [CrossRef]

21. Laloux, T.; Junqueira, B.; Maistriaux, L.C.; Ahmed, J.; Jurkiewicz, A.; Chaumont, F. Plant and Mammal Aquaporins: Same but Different. Int. J. Mol. Sci. 2018, 19, 521. [CrossRef]

22. Morinaga, T.; Nakakoshi, M.; Hirao, A.; Imai, M.; Ishibashi, K. Mouse aquaporin 10 gene (AQP10) is a pseudogene. Biochem. Biophys. Res. Commun. 2002, 294, 630-634. [CrossRef]

23. Baumgarten, R.; Van De Pol, M.H.; Wetzels, J.F.; Van Os, C.H.; Deen, P.M. Glycosylation is not essential for vasopressin-dependent routing of aquaporin-2 in transfected Madin-Darby canine kidney cells. J. Am. Soc. Nephrol. 1998, 9, 1553-1559. [CrossRef]

24. Hendriks, G.; Koudijs, M.; van Balkom, B.W.; Oorschot, V.; Klumperman, J.; Deen, P.M.; van der Sluijs, P. Glycosylation is important for cell surface expression of the water channel aquaporin-2 but is not essential for tetramerization in the endoplasmic reticulum. J. Biol. Chem. 2004, 279, 2975-2983. [CrossRef]

25. Umenishi, F.; Narikiyo, T.; Schrier, R.W. Effect on stability, degradation, expression, and targeting of aquaporin-2 water channel by hyperosmolality in renal epithelial cells. Biochem. Biophys. Res. Commun. 2005, 338, 1593-1599. [CrossRef]

26. Casares, L.; Garcia, V.; Garrido-Rodriguez, M.; Millan, E.; Collado, J.A.; Garcia-Martin, A.; Penarando, J.; Calzado, M.A.; de la Vega, L.; Munoz, E. Cannabidiol induces antioxidant pathways in keratinocytes by targeting BACH1. Redox Biol. 2020, $28,101321$. [CrossRef]

27. Boury-Jamot, M.; Daraspe, J.; Bonte, F.; Perrier, E.; Schnebert, S.; Dumas, M.; Verbavatz, J.M. Skin aquaporins: Function in hydration, wound healing, and skin epidermis homeostasis. Handb. Exp. Pharmacol. 2009, 205-217. [CrossRef] 
28. Ikarashi, N.; Kon, R.; Kaneko, M.; Mizukami, N.; Kusunoki, Y.; Sugiyama, K. Relationship between Aging-Related Skin Dryness and Aquaporins. Int. J. Mol. Sci. 2017, 18, 1559. [CrossRef] [PubMed]

29. Ikarashi, N.; Mizukami, N.; Kon, R.; Kaneko, M.; Uchino, R.; Fujisawa, I.; Fukuda, N.; Sakai, H.; Kamei, J. Study of the Mechanism Underlying the Onset of Diabetic Xeroderma Focusing on an Aquaporin-3 in a Streptozotocin-Induced Diabetic Mouse Model. Int. J. Mol. Sci. 2019, 20, 3782. [CrossRef] [PubMed]

30. Ikarashi, N.; Mizukami, N.; Pei, C.; Uchino, R.; Fujisawa, I.; Fukuda, N.; Kon, R.; Sakai, H.; Kamei, J. Role of Cutaneous Aquaporins in the Development of Xeroderma in Type 2 Diabetes. Biomedicines 2021, 9, 104. [CrossRef] [PubMed]

31. Kim, N.H.; Lee, A.Y. Reduced aquaporin3 expression and survival of keratinocytes in the depigmented epidermis of vitiligo. J. Investig. Dermatol. 2010, 130, 2231-2239. [CrossRef]

32. Lee, A.Y. Role of keratinocytes in the development of vitiligo. Ann. Dermatol. 2012, 24, 115-125. [CrossRef]

33. Lee, Y.; Je, Y.J.; Lee, S.S.; Li, Z.J.; Choi, D.K.; Kwon, Y.B.; Sohn, K.C.; Im, M.; Seo, Y.J.; Lee, J.H. Changes in transepidermal water loss and skin hydration according to expression of aquaporin-3 in psoriasis. Ann. Dermatol. 2012, 24, 168-174. [CrossRef] [PubMed]

34. Ikarashi, N.; Kaneko, M.; Watanabe, T.; Kon, R.; Yoshino, M.; Yokoyama, T.; Tanaka, R.; Takayama, N.; Sakai, H.; Kamei, J. Epidermal Growth Factor Receptor Tyrosine Kinase Inhibitor Erlotinib Induces Dry Skin via Decreased in Aquaporin-3 Expression. Biomolecules 2020, 10, 545. [CrossRef] [PubMed]

35. Hara, M.; Verkman, A.S. Glycerol replacement corrects defective skin hydration, elasticity, and barrier function in aquaporin-3deficient mice. Proc. Natl. Acad. Sci. USA 2003, 100, 7360-7365. [CrossRef] [PubMed]

36. Rodriguez, A.; Catalan, V.; Gomez-Ambrosi, J.; Garcia-Navarro, S.; Rotellar, F.; Valenti, V.; Silva, C.; Gil, M.J.; Salvador, J.; Burrell, M.A.; et al. Insulin- and leptin-mediated control of aquaglyceroporins in human adipocytes and hepatocytes is mediated via the PI3K/Akt/mTOR signaling cascade. J. Clin. Endocrinol. Metab. 2011, 96, E586-E597. [CrossRef] [PubMed]

37. Choudhary, V.; Olala, L.O.; Qin, H.; Helwa, I.; Pan, Z.Q.; Tsai, Y.Y.; Frohman, M.A.; Kaddour-Djebbar, I.; Bollag, W.B. Aquaporin-3 re-expression induces differentiation in a phospholipase D2-dependent manner in aquaporin-3-knockout mouse keratinocytes. J. Investig. Dermatol. 2015, 135, 499-507. [CrossRef] [PubMed]

38. Chiadak, J.D.; Arsenijevic, T.; Gregoire, F.; Bolaky, N.; Delforge, V.; Perret, J.; Delporte, C. Involvement of JNK/NFkappaB Signaling Pathways in the Lipopolysaccharide-Induced Modulation of Aquaglyceroporin Expression in 3T3-L1 Cells Differentiated into Adipocytes. Int. J. Mol. Sci. 2016, 17, 1742. [CrossRef]

39. Fruhbeck, G.; Balaguer, I.; Mendez-Gimenez, L.; Valenti, V.; Becerril, S.; Catalan, V.; Gomez-Ambrosi, J.; Silva, C.; Salvador, J.; Calamita, G.; et al. Aquaporin-11 Contributes to TGF-beta1-Induced Endoplasmic Reticulum Stress in Human Visceral Adipocytes: Role in Obesity-Associated Inflammation. Cells 2020, 9, 1403. [CrossRef] [PubMed]

40. Pertwee, R.G. The diverse CB1 and CB2 receptor pharmacology of three plant cannabinoids: Delta9-tetrahydrocannabinol, cannabidiol and delta9-tetrahydrocannabivarin. Br. J. Pharmacol. 2008, 153, 199-215. [CrossRef] [PubMed]

41. Parray, H.A.; Yun, J.W. Cannabidiol promotes browning in 3T3-L1 adipocytes. Mol. Cell. Biochem. 2016, 416, 131-139. [CrossRef] [PubMed]

42. Sonego, A.B.; Prado, D.S.; Vale, G.T.; Sepulveda-Diaz, J.E.; Cunha, T.M.; Tirapelli, C.R.; Del Bel, E.A.; Raisman-Vozari, R.; Guimaraes, F.S. Cannabidiol prevents haloperidol-induced vacuos chewing movements and inflammatory changes in mice via PPARgamma receptors. Brain. Behav. Immun. 2018, 74, 241-251. [CrossRef] [PubMed]

43. Jiang, Y.J.; Kim, P.; Lu, Y.F.; Feingold, K.R. PPARgamma activators stimulate aquaporin 3 expression in keratinocytes/epidermis. Exp. Dermatol. 2011, 20, 595-599. [CrossRef]

44. Ikarashi, N.; Sato, W.; Toda, T.; Ishii, M.; Ochiai, W.; Sugiyama, K. Inhibitory Effect of Polyphenol-Rich Fraction from the Bark of Acacia mearnsii on Itching Associated with Allergic Dermatitis. Evid. Based Complement. Alternat. Med. 2012, 2012 , 120389. [CrossRef] [PubMed] 